DOI: $10.12957 /$ teias.2022.60595

\title{
AMBIVALÊNCIA, EDUCAÇÃO E SOLIDARIEDADE EM DIÁLOGO: caminhos de formação para a pluralidade
}

Resumo

Os tempos líquidos que, neste momento da história da humanidade, compartilhamos, convocam a refletir alternativas de enfrentamento à crescente violência, despolitização, captura e desautorização do pensamento científico. Dispor-se ao diálogo e à solidariedade educa pelo compromisso com a vida e pela gestualidade que, eticamente, enriquece as experiências cotidianas, concretas e das narrativas. Em atenção à temática da educação, do conhecimento e da identidade no mundo da pluralidade sociocultural, pelo olhar da filosofia social, objetiva-se ensaiar acerca da solidariedade como ponto de partida para a pluralidade e para o compromisso dialógico na perspectiva metodológica da hermenêutica pluralizadora, ainda que sem a pretensão de fundamentos e soluções teleológicas, porém, com intencionalidades reflexivas e propositivas. Os caminhos teóricos se constituem, para esta elaboração, no lastro metodológico da ambivalência/plurivalência, em categorias paradigmáticas, a partir de Bauman, e mostram-se potentes para pensar processos educativos como possibilidades de construção do conhecimento, da solidariedade e do diálogo, afetivo, acolhedor e sensível à pluralidade e compromissos éticos desde os vínculos humanos e, para eles também dirigidos. Pensadores e vertentes diversas são chamados para a tematização, pois, de seus lugares de compreensão e elaboração, se aproximam da validade do pensamento plural como instituinte de perspectivas. Pensar a educação orientada para a solidariedade coloca-se como possibilidade de resistência às imposições anatemáticas que violam a condição humana da dignidade e do diálogo como espaço de constituição das subjetividades, do mundo da vida e das vivências formadoras da pluralidade.

Palavras-chave: educação; solidariedade; diálogo; Zygmunt Bauman; ambivalência/plurivalência.

\section{AMBIVALENCE, EDUCATION AND SOLIDARITY IN DIALOGUE:} formation path for plurality

\begin{abstract}
The shared times of this liquid modernity call for reflections that thematize alternatives to combat the increasing wave of violence, depolitization, seizing and decommitment of the thought and scientific construction, of the humanitarian rationality. Being ready for dialogue and solidarity educates through commitment to life and enriches experiences. In view of the theme of education, knowledge and identity in the world of socio-cultural plurality, from the perspective of social philosophy, the objective is to look at welcoming as a starting point for plurality and ecological commitment, in the pluralizing hermeneutic perspective without the pretension of fundamentals and teleological solutions, but purposeful intentions. The Bauman pluralizing hermeneutic perspective is assumed and, by its influence, dialectically, it is brought close to the perspectives without the intention to present teleological foundations and solutions, but bringing to the discussion intents of proposals. The theoretical ways are built from the ambivalence/plurivalence, taken as paradigmatic categories from Bauman and potentially full of meanings to expand comprehensions about the educative process as possibilities of construction of knowledge from the dialogical relations, emotional, welcoming, sensitive to the plurality and engaged to human links.
\end{abstract}

Keywords: education; solidarity; dialogue; Zygmunt Bauman; ambivalence/plurivalence. 
Resumen

Los tiempos líquidos compartidos llaman a reflejar alternativas de enfrentamiento de la creciente violencia, despolitización, captura y desautorización del pensamiento científico. Disponerse al diálogo y la solidaridad educa por lo compromiso con la vida y enriquece las experiencias. Estar dispuesto al diálogo y la solidaridad educa a través del compromiso con la vida y enriquece las experiencias. Frente al tema de la educación, el conocimiento y la identidad en el mundo de la pluralidad sociocultural, desde la perspectiva de la filosofía social, se busca mirar a la acogida como punto de partida de la pluralidad y el compromiso ecológico, en la perspectiva hermenéutica pluralizadora sin la pretensión de fundamentos y soluciones teleológicas, pero intenciones resueltas. Los caminos teóricos se constituyen a partir de la ambivalencia/ plurivalencia, categorías paradigmáticas a partir de Bauman y potentes para pensar procesos educativos como posibilidades de construcción del conocimiento dialógico, afectivo, acogedor y sensible a la pluralidad y compromisos con los vínculos humanos.

Palabras clave: educación; solidaridad; diálogo. Zygmunt Bauman; ambivalencia/plurivalencia.

\section{PALAVRAS INICIAIS}

No lastro teórico de Zygmunt Bauman e da hermenêutica pluralizadora, colocamos em diálogo pensadores do campo sócio-filosófico para pensar a educação, o conhecimento e a identidade no mundo da diversidade social e cultural. Tematizamos a solidariedade e a educação como diálogo necessário, na perspectiva da plurivalência, com o objetivo de indicar o horizonte das urgentes resistências desde o mundo compartilhado neste estágio da humanidade. Compreendemos, juntamente com Bauman (2016; 2017) e Freire (2014), que a dimensão da solidariedade, da educação, da ciência, do cuidado e do compromisso com a alteridade sugerem condições de tratamento dos espaços vivenciados e do desenvolvimento das experiências que, neste ensaio, denominamos vida. Esse mundo que compartilhamos é ambivalente, complexo, plural, contingente, porém, amplo em possibilidades, assim como é desenhado, organizado e em funcionamento a partir das concepções historicamente hegemônicas.

Nesta perspectiva de escrita, seguimos pela metodologia dialética e hermenêutica, em esforço de diálogo para, desse modo, encaminhar as intencionalidades do texto, no amparo que encontramos em Stein (2018) e Bauman (2018), preocupados, respectivamente, com o conhecimento e a dignidade humana. Talvez, entre todas as encruzilhadas possíveis, aquelas do diálogo, da educação, da ciência, da proximidade e acolhida, têm sido as mais distantes e merecem, aqui, uma atenção sob o olhar pluralizador da metodologia hermenêutica. Ao fechar a porta atrás de si, a humanidade rompe essencialidades da condição humana que acentuam riscos de desintegrações desvinculadas da cosmologia da vida e autorizam experiências na obscura irracionalidade de mundos, também possíveis, porém, egoístas, fundamentalistas, mascaradas e iniciantes da pauta das violências, dos domínios absolutistas e estritamente personalistas.

Pensar a educação e a solidariedade no contexto das vulnerabilizações provocadas pela crescente onda neoliberal das volatilizações de valores, dos sentimentos, da pesquisa, da singular e especial capacidade humana da reflexão, se mostra alternativa exigente de mergulho no mundo líquido para encontrar ilhas de alguma materialidade consistente na qual os barcos da existência possam ser ancorados e os jardins da existência, cultivados com a metodologia da pluralidade. Esta perspectiva desenvolve a presente reflexão que ensaia no horizonte da educação e da solidariedade ou, ousadamente, na via da educação para a solidariedade, assim como também já o fez Paulo Freire (2014), propondo-se pensar alternativas de resistências à expansão das raivosidades e violências que se assomam no mundo fundamentalista e dogmatizante no qual se instala a verdade suprema e esvazia o espaço da cientificidade, da dialogicidade e, inclusive, das racionalidades, cognitividades 
e emotividades enquanto constituintes da manutenção e defesa da vida. Nessa linha metodológica e de compreensão, também se exerce um esforço de diálogo entre tradições de pensamento que entendemos, desde a ambivalência, possíveis, pois se colocam como diversidades teóricometodológicas sem descuidar do grande e central problema da dignidade humana e da continuidade da vida, pelas vias da educação e da solidariedade (FREIRE, 2014).

Entre as primeiras palavras, para traçar a arqueologia da presente reflexão, compreendemos a educação enquanto espaço de vivências e experiências capazes de despertar reflexões que educam e, por isso, campo de relações políticas, pois se desenvolvem entre indivíduos com concepções diferentes, distintas, plurais. Ao marcar essas abordagens e metodologias de análise textual e de conteúdo, apresenta-se a alegoria do jardineiro que, na ambivalência e paradoxo, na âncora do pensamento de Bauman, para quem o Estado Moderno - da modernidade sólida - assume características de regramentos radicais, incorporação da estética da igualdade, defensor do pensamento único e simpático a regulações hegemonizantes, implanta e defende um projeto de segurança, de uniformidade, de seleção e padronização que aborta as subjetividades, as amplitudes dialógicas e dificulta relações intersubjetivas que educam pela gestualidade de suas manifestações e ocorrências. No contraponto do Estado centralizador, o jardineiro da imagem, aqui em apresentação, é republicano, de uma democracia participativa e em gestação na estética da pluralidade, assim como, também, desenha-se a perspectiva deste ensaio de base baumaniana.

A contingência, enquanto uma espécie de consciência da ambivalência, presente nas realidades concretas e no imaginário, na existência e na linguagem, no mundo da vida, no mundo concreto, indica a possibilidade de compreender e, por vezes, explicar o mundo pelas vias de um paradigma novo, possivelmente em gestação (CASSOL; PITHAN DA SILVA, 2019), que pode ser denominado de ambivalência ou plurivalência (CASSOL, 2020) e, apresenta alguma potencialidade interessante de orientações para novos projetos.

O modo como os indivíduos precisam ver o mundo, como carecem pensá-lo e como viver nele não está pronto - e, tampouco, está determinado. Em um primeiro diálogo, podemos pensar com Pedro Demo (2000, p. 59) e aprender que "é a incerteza que traz oxigênio novo para nossas certezas". Ela, a incerteza transporta, também, desafios para a ciência como possibilidades de evoluir, de crescimento, de desenvolvimento. Desse modo, "incerteza não é conceito negativo, embora psicológica e socialmente falando o possa ser. Mas, epistemológica e ontologicamente falando, incerteza é a marca da tessitura da realidade. [...] é modo de ser que é vir-a-ser" (DEMO, 2000, p. 60). Aqui se apresenta uma demonstração da dinâmica do paradigma ambivalente/plurivalente que este texto adota como metodologia e base teórica e permite visualizar possibilidades no campo da educação como formação com condições de encaminhar sentidos de solidariedade.

\section{POSSIBILIDADES DE EDUCAR NO OLHAR AMBIVALENTE/PLURAL DA FILOSOFIA SOCIAL}

O compromisso sócio-filosófico da educação e da própria pedagogia não se restringe à atitude de ensinar. Ao ultrapassar o conhecer linear das disciplinas, das áreas, bem como, ao se utilizar desses conhecimentos básicos, fundamentais, a ética educacional provoca uma crítica pessoal, uma autocrítica, no sentido de fornecer as condições para que os indivíduos possam realizar críticas de si mesmos, das suas vidas, das suas existências, de suas histórias, dos seus momentos, das suas perspectivas, como uma possibilidade reflexiva e de criação. De algum modo, ainda que não definitivo, "A criatividade só é possível em ambiente de incerteza” (DEMO, 2000, 
p. 9). Nesse campo, também dialogam tradições de pensamento que, desde suas diversidades, empreendem esforços de aproximação à medida que a preocupação fundamental seja a continuidade da vida e a dignidade humana.

Esse pensar-se compõe a atitude primeira da sócio-filosofia na proporção em que possibilita e conduz os indivíduos a reflexões de suas possibilidades, de suas potencialidades, de suas histórias e condições. Essa postura dialógica de reconhecimento/autoconhecimento, enquanto atitude sócio-filosófica, é educativa pois tensiona a força do apassivamento, das hegemonizações e homogeneizações. A filosofia social trata aqui da perspectiva do indivíduo - e de compreensões teóricas - que não se limita a si próprio enquanto satisfação absoluta, mas aproxima-se da sociologia do indivíduo, no sentido tecido por François de Singly (2006) ao referir que, desse modo, o individualismo pode criar laços. Laços não de aprisionamento e amarras, mas, sim, de vinculações sociais e inserções pessoais com potencialidade enxergar a alteridade e, desde esse lugar, a diversidade presente no mundo, existente para além do próprio indivíduo, das suas necessidades e demandas apenas.

Nesse caminho, se estabelecem vínculos das reflexões subjetivas com o despertar para as visibilidades e os movimentos de aproximações e compreensões em relação aos demais indivíduos e às diversas teorias. A ambivalência presente nesses campos, é contingência, aceitação ética das insuficiências, das limitações e impossibilidades do envolvimento com o todo, inaugura o diálogo e aproxima posições para estabelecer conexões e, desse modo, maior amplitude, maior alcance, maior compreensão. A filosofia, enquanto reflexão desde si, não absolutiza posições e compreensões - tanto dos indivíduos quanto das tradições de pensamento -, mas democratiza, partilha e amplia os horizontes de realizações individuais com as demandas coletivas.

A abertura das subjetividades para o encontro ao outro/à outra, se coloca na dialogicidade das necessidades desencadeadas pelas potencialidades ininterruptas da reflexividade que pode originar-se no indivíduo e ampliar-se, em perspectiva social para a comunidade assim como, pelo despertar das demandas coletivas, impulsionar e despertar para as condições e necessidades do desenvolver filosófico e teórico. A filosofia social que pode, na teoria de Bauman, ser a própria sociologia, apresenta-se como inquietação, desacomodação porque passa a incomodar, como é próprio da ambivalência/pluralivalência porque se sabe contingente, em função de que "Não é a reverência que nos faz aprender, mas a ousadia de não deixar nada intocável" (DEMO, 2020, p. 10). Especialmente, quando o objeto da reflexão é a dignidade humana e a justiça social, temas caros para Bauman e, igualmente, para Freire, sem os quais nem a educação, nem a solidariedade se efetivam.

Na compreensão de Bauman, a ambivalência é constituinte da realidade, da vida e provoca uma filosofia social ampliada que permite hermenêuticas plurais. É possível pensar, nessa linha teórica com Ortiz-Osés, para quem a ambivalência revela a pluralidade social e, então, uma filosofia social e uma sociologia da educação que "Consiste en comprender que toda nuestra existencia, incluida la realidad del universo, es ambivalente [...]. Asumir la ambivalencia de todo es asumir flexiblemente la realidad [...] y no dejarse llevar por los extremos o extremismos, estar abierto al devenir [...]. La ambivalencia nos salva de toda unilateralidade [...]" (BERGUA, 2020). A dialogia desse sentido, mostra que filosofia social não se afasta da sociologia, antes, é ela própria. Unificase para encontrar possibilidades de compreensão dos fatos, das situações, das circunstâncias e contextos que envolvem os indivíduos nas suas relações, as sociedades e os processos instituintes (CASTORIADIS, 2004), pois são, constitutivos das dinâmicas entre as reflexões, as compreensões, as elaborações dos indivíduos e as interferências da comunidade e/ou das sociedades sobre o próprio pensar, as atitudes e a cultura dos indivíduos. 
A relevância da primeira atitude da filosofia social e da sociologia da educação se concentra na possibilidade de despertar os indivíduos para que se vejam, eles próprios, sujeitos de demandas, de necessidades, de desejos e desse ponto, como sugere François de Singly (2006), possam ver, também, a alteridade, os outros/as outras, como indivíduos em demanda, repletos de desejos e necessidades e carentes de efetividade em seus projetos. Pode-se dizer que essa primeira atitude social da filosofia, ainda que requeira reflexão e crítica, é uma atitude humanizadora porque faz com que os indivíduos se entendam como seres humanos (CASSOL, 2008) não absolutos e suas posições e sentidos de suas compreensões. A apropriação dessa condição se transforma em perigo para as hegemonias poderosas e estruturas solidificadas à medida que pode viabilizar a consciência da condição individual e compreender a realidade e as relações, como ainda ensina Gramsci (2004, p. 58) - em outro diálogo possível com Bauman - ao indicar que a consciência de seu próprio valor e do valor coletivo da sociedade "se forma não sob a pressão brutal das necessidades fisiológicas, mas através da reflexão inteligente [...] sobre as razões de certos fatos e sobre os meios para convertê-los, de ocasião de vassalagem, em bandeira de rebelião e de reconstrução social".

A proposta gramsciana, associa-se, na compreensão deste ensaio, à ambivalência social que envolve a educação, não como acontecimento negativo, mas potencialidade do reconhecimento das contingências, das insuficiências de sentidos, de reflexões e de atitudes para os processos de mudanças e construções sócio-culturais. Porém, justamente, da consciência das não totalizações, das fragilidades conceituais, surgem as perspectivas de diálogo e solidariedade para a ação educacional (FREIRE, 2014; BAUMAN, 2016; 2017) na âncora da sociologia e da filosofia. A ciência parece, então, se desenvolver não pelo viés da totalização, mas do reconhecimento das fragilidades, das desconexões e incapacidades explicativas. Move-se, humildemente, a partir do reconhecer das insuficiências, das contingências e, portanto, das ambivalências e plurivalências, para novas construções, novos projetos e em direção a alternativas educadoras e formativas. Saberse não totipotente é consciência já em processo educador, formativo, diálogo e de aproximação ao que, em algum momento, pode ser considerado estranho e, até mesmo, anatemático.

Compreende-se que quando a pessoa se entende como ser humano, se compreende indivíduo, começa a posicionar-se em um lugar de responsabilizações que podem ser pessoais e, também, coletivas. Ao se descobrir de vontades e desejos, emerge uma consciência que impele ao entendimento de si mesmo/si mesma como portador/portadora de potencialidades e possibilidades. Ao ver-se como um ser que pensa e demanda, passa a cobrar mais espaços, mais ações dos governos, do Estado; ainda, persegue e conquista seus espaços na família, na escola, na sociedade, nas instituições, porque reconhece sua condição, sua humanidade. O empoderamento libera a força das demandas no sentido das ações do Estado que o dignifiquem e o qualifiquem enquanto tal: como pessoa humana que não está só, mas inserida em uma comunidade. Essa consciência vista por Gramsci, desde sua perspectiva teórica, pode estar acompanhada da possibilidade de que aquilo que pretende para si, pode, igualmente, querer desejar para o outro/a outra, para a coletividade. Há aqui uma possibilidade de diálogo entre as diferentes tradições de pensamento tanto com John Rawls, da equidade, quanto com Bauman na perspectiva da condição e da dignidade humana.

Ao proporcionar essa atitude do pensar, da autorreflexão, do reconhecer-se como pessoa, a filosofia social insere-se na dimensão dialógica e da solidariedade e oportuniza um momento de reconhecimento do outro/da outra a partir do empoderamento do indivíduo que assume a potência de desencadear um pensamento que principia a reconhecer que ele não está sozinho no mundo, mas é um sujeito comunitário, um ser político, um ser de construção de relações e, então, passa a ver o outro/a outra também como necessário à sua vida, constitutivo da sua pessoa, integrante das relações diárias e cotidianas que o fazem crescer e fazem crescer a sociedade também (CASSOL, 
2008). Não abdica, desse modo, da incorporação da diversidade, da pluralidade, tanto das teorias nas suas perspectivas constitutivas e analíticas - quanto das posições e compreensões dos demais indivíduos, para dar mais amplitude às compreensões, pois entende que as contingências, as ambivalências, são constituintes do mundo concreto e do mundo da vida. A filosofia social é, nesse pensamento, com e a partir de Bauman, a própria sociologia na metodologia pluralizadora e, mesmo, sociologia hermenêutica. Nesse momento, o indivíduo pode tomar consciência de suas ações e das que o envolvem de algum modo desde os outros/as outras com as quais estabelece relações, oportunidade em que se dá a formação de um ser político porque dialógico. Esse processo de educação tem se apresentado como carência histórica, mas pode carregar "[...] o espírito da solidariedade desinteressada, do amor pela livre discussão, do desejo de buscar a verdade com meios unicamente humanos, tais como os fornecidos pela razão e pela inteligência" (GRAMSCI, 2004, p. 125).

A filosofia social - enquanto reflexão desde si, das subjetividades, dos indivíduos para a amplitude comunitária ou, igualmente, desde o campo social como elemento para as problematizações e análises em perspectiva individual - e a sociologia da educação - enquanto possibilidades de análise e compreensão das circunstâncias e contextualidades ampliadas que implicam e impactam os fatores constituintes da formação dos indivíduos e as interferências socioinstitucionais que, de algum modo, também os produzem - são formadoras do sujeito político, do indivíduo que concebe a consciência de sua existência e a consciência do seu mundo e, desses horizontes, a própria comunidade/sociedade. Um mundo que, para responder às necessidades pessoais e coletivas, não pode ficar individualizado, fragmentado, mas deve ser compartilhado. Nessa perspectiva, "Uma educação que se compõe, se expressa, se constitui e faz sentido nas vivências e experiências dos educandos, contribui para a confiança, o reconhecimento da ação humana e da solidariedade" (VANI, 2019, p. 121). Constitui-se, nessa dimensão, um mundo de solidariedade e forma-se uma sociedade onde há clara compreensão de que os outros também participam e constroem como seres solidários, indispensáveis no processo de construção de uma sociedade que pensa a condição humana, política e ecológica.

Pode ser por esta via que a atitude primeira da filosofia social faz nascer no sujeito estudante, o ver-se, o perceber-se, entender-se como pessoa, como indivíduo e, a partir daí, cidadão. O momento autorreflexivo em que o ser toma consciência de si e passa a ser um sujeito político, inclui várias relações intensamente progressivas: 1) a descoberta de si como pessoa; 2) a pessoa toma consciência do outro e, logo após, dos outros - consciência comunitária -; 3) o momento em que a pessoa descobre as relações institucionais, um mundo de possibilidades relacionais. Ao descobrir as instituições, as entende como criações humanas e passíveis de mudanças, de transformações, assim como é próprio da condição humana.

Porém, mesmo que o projeto da ambivalência com objetivos de ampliar os horizontes de compreensão, inserir o diálogo e a solidariedade na práxis que educa pela atitude, pela metodologia e pelo conhecimento em produção, a paixão por "entender e a humildade proveniente da percepção de que provavelmente a tarefa da compreensão jamais será concluída”, paralela à "[...] convicção de que é precisamente essa consciência da incompletude que torna o comentário do estudioso da sociologia valioso para pessoas que enfrentam diariamente os desafios da vida (BAUMAN, 2011, p. 30) permanecem centrais nos movimentos de construção dos conhecimentos. Nessa atitude, a filosofia social e a sociologia da educação operam na compreensão da complexidade, mas transcendem o sentido de que a complexidade existe somente na coisa, na realidade, no concreto. Bauman parece compreender que a coisa, o objeto, é constituído de complexidade; a complexidade compõe a coisa, o objeto, o mundo, mas também o modo como se vê a coisa, como se interpreta, então, o próprio sujeito que investiga, que aprende e, desse modo, pode dialogar com a construção 
teórica de Maturana e Varella. Enquanto sociologia atua no esforço de compreensões e explicações da complexidade que constitui e institui as comunidades e as sociedades, bem como interferem nas subjetividades como educação e formação dos indivíduos, seus espaços de experiências e vivências.

Evidencia-se, nessa abordagem, um Bauman consciente da complexidade, mas a vê sempre como ambivalente à medida que a compreensão e a análise operam na contingência. Aqui não há, propriamente, um mal, mas o princípio de uma ação consciente para o diálogo, um movimento de aproximar-se do diferente, da outra tradição, um estranhamento que indica a existência de plurivalências e incita novas buscas. A ambivalência é convocação para a pluralidade porque exige a alteridade e lança a abertura para a comunidade. O filósofo espanhol Ortiz-Osés parece reforçar essa compreensão, ao defender, em entrevista uma criatividade cultural aberta ao outro, à outreidade, de modo radical, pois

\begin{abstract}
[...] la procreación es el modelo de toda creación o creatividad humana, la cual consiste en acceder al límite o frontera y transitarla culturalmente, o sea, en penetrar simbólicamente en la otredad, lo que es propio de la ciencia, o bien ser penetrado simbólicamente por la otredad, lo que es propio de la conciencia. Por eso en el fondo de toda pro-creación está agazapado el amor, ya que en el amor yo soy otro, porque hay un proceso de otración o transformación radical. Crear es procrear simbólicamente, es decir, culturalmente. (BERGUA, 2020).
\end{abstract}

A existência da ambivalência, da pluralidade, assume a condição de paradigma a partir de Bauman e se apresenta no mundo humano/mundo comum da diversidade e da diferença, portanto, da ampliação dos horizontes de interpretação, mas como na proposta de Ortiz-Osés e Maturana e Varella é necessário mover-se na direção da acolhida, do afeto, do carinho e criar, desde esses horizontes, a ciência, o conhecimento e os processos de aprendizado com as forças da educação no caminho do diálogo visualizando o mundo da solidariedade. O percurso teórico de Bauman, nesse contexto, sugere considerar as várias tradições de pensamento e o uso abundante de metáforas porque fazem pensar e demonstram que incorporar as metodologias pluralizadoras dos sentidos, das narrativas, das interpretações do mundo, expõem a seriedade da contingência das compreensões e a consciência de que as alternativas, as vias, as possibilidades, não são únicas, não são absolutas, tanto da dimensão do concreto, do real, quanto do imaginário, do simbólico, das interpretações.

\title{
REFLEXÕES PARA PENSAR A EDUCAÇÃO EM DIÁLOGO COM A VIDA E A SOLIDARIEDADE
}

Grande número de pensadores e pensadoras têm repetido que não há aprendizado sem conteúdo, sem leitura, estudo e, por conseguinte, produção de conhecimento e sentidos. Contudo, os processos, as metodologias, dessa construção, precisam assumir uma condição de centralidade com potência na mobilização da consciência/autoconsciência, como compreende Gramsci (2004), de si e do outro/da outra. Abre-se a perspectiva de desenvolver, de germinar, o conhecimento, o aprender, no incentivar a compreensão da complexidade da sociedade, da ciência, do contexto sócio-histórico e cultural. O ser humano, provido de alguma capacidade racional, apresenta, ainda que potencialmente, condições de compreensão, de decisão e de ação. Por força biológica, parece realizar esses movimentos em relação ao que lhe é vital em relação intrínseca ao que compreende, de modo que a ação de cada indivíduo é acontecimento motivado pela convicção pessoal, subjetiva, da sua validade ou da preservação da vida. A ação segue a decisão do valor da ação ou a impossibilidade de decidir de outro modo. O humano age por estar convicto da necessidade e da 
validade da ação ou por não ter condições de agir de outro modo. No entanto, parece sempre mover-se no sentido da ação que mais amplamente - segurança - pode permitir vida.

Pensar que a ação educadora tenha condições de agir no horizonte da vida ou que, talvez, seja aí mesmo onde ela interfira primordialmente, pode acalentar uma possibilidade, por isso, não única, de despertar para o valor que a dignidade humana, a segurança, a autonomia, assumem na perspectiva da condição humana. É bem verdade que a formação, nesse caminho, não consiste em lições pragmáticas e imediatas de como realizar o bem - condições que também não podem ser desconsideradas -, mas se afirmam na viabilidade do pensar, da reflexão e do estabelecer compreensões de mundo. O humano não pode abdicar da possibilidade humana mesmo ao compreender que a condição humana é ambivalente. A consciência da ambivalência dinamiza a compreensão da incoerência dialógica do pensamento único que dizima a pluralidade e frustra a capacidade criadora. Mesmo do individualismo, como pensa Singly e da sociedade de consumidores, no alerta Bauman, é possível pensar o labirinto na lógica da impermanência, da superação. A racionalidade, por si só, porém, não converge naturalmente, sempre e incondicionalmente a favor da vida. A necessidade, limitada no seu aspecto racional, portanto, não autônoma, ocupa essa dimensão da vida, mas, não supre tanto a deficiência quanto à possibilidade.

No âmbito da sociologia da educação e da filosofia social, a verdade e a educação se aproximam, se identificam, se relacionam na ambivalência da vida, dos sentidos, na proposta de Bauman. Filosofia que pensa a vida desde o indivíduo não isolado, mas em constante relação e sociologia que compreende e explica o espaço de formação, atuação e construção do indivíduo. Parece ser a proposta de Ortis-Osés ao compreender que,

En efecto, la verdad es de todos y todas y de nadie en particular, porque la verdad no es posesión de nadie. La verdad es inter-verdad, verdad dialógica y democrática, verdad encarnada como sentido existencial y no como una esencia o fundamento dogmático. La verdad es humana, intersubjetiva y relacional, y no absoluta o absolutista pero tampoco meramente relativista. La verdad es paradójicamente implicación de contrarios, mediación y remediación de los opuestos, lo que incluye una política del consenso pragmático frente à la trinchera ideológica cerril. Esta mediación hay que realizarla desde un centro descentrado y desde un medio dinámico o remediador y no estático ni obturador. (BERGUA, 2020).

Mesmo no apressamento de aproximar a ambivalência com a educação, e daí colher a possibilidade do diálogo e a semente da solidariedade, pode-se mover para pensar que o ensino das certezas não enriquece; ele é importante, mas precisa ser compreendido como insuficiente. Assim, na compreensão, na consciência da ambivalência/plurivalência, a ciência avança, o conhecimento é construído e as capacidades cognitivas e relacionais dos indivíduos são ativadas. Elas não adormecem. Bauman tem uma crítica séria a essa questão da "oclusão mental", que aprende de Pierre Bourdieu da "leitura oblíqua", para ilustrar a educação como movimento para a vida toda. A ambivalência/plurivalência se apresenta paradigmática desde o horizonte da hermenêutica pluralizadora, pois, coloca-se distante das estruturações sistemáticas da racionalidade instrumentalizadora e fragmentadora da modernidade, para a resistência às verdades dogmáticas e fundamentalistas. É, no entanto, essa mesma ambivalência que permite pensar, a partir de Bauman, as possibilidades teóricas do mundo da educação e da vida e problematizar a dinâmica existencial, evolutiva e complexa da condição humana.

Bauman não se deixa vencer pelo encantamento com a pós-modernidade: cético diante dela, a tematiza compreendendo sua contribuição para a pluralidade de vias/possibilidades na 
realização das demandas dos indivíduos; mas, também temeroso ante diluições e volatilizações que os tempos compartilhados do presente procuram impor. Há valores ainda possíveis onde ancorar o barco e mirar saídas. A educação para a solidariedade, talvez, se constitua em alternativa da condição humana como um residual em meio às diluições da liquidez, uma via possível na pluralidade/multiplicidade/diversidade de caminhos do mundo compartilhado. $\mathrm{Na}$ educação solidária, os conhecimentos se constituem por meio das relações, das vivências e convivências com os outros e com o mundo, também, entre diálogos com tradições plurais de pensamento. Uma possibilidade de promoção nas mudanças dos valores, da cultura, da ciência e da convivência humana. Ela, a solidariedade, é responsável pela coesão, pela identidade e pela constituição dos valores e dos vínculos solidários estabelecidos entre os indivíduos e nas relações humanas. Percebese, nessa concepção, o recurso baumaniano ao diálogo de onde, para ele - aproximado do pensamento habermasiano -, brota o construir das visualizações de vias possíveis e possibilidades de novos caminhos. Pode ser nesse sentido que o diálogo, na compreensão baumaniana, não tem sentido entre iguais, pois nesse âmbito ele já acontece, pois é natural. Todavia, na diferença, nas divergências, nos conflitos, nos estranhamentos/nos tensionamentos - também ocorrências naturais da condição humana -, ele, o diálogo, se aproxima da solidariedade e abre caminhos.

Processos educativos que podem se desenvolver desde um horizonte paradigmático ambivalente/plurivalente têm a perspectiva de ensinar o quanto é preciso relativizar as certezas e dispor-se ao diálogo. Para Bauman (2014, p. 31), "No hay una senda benigna, fácil de transitar y a prueba de daños colaterales, que conduzca a obedecer las normas de la vida civilizada". Desse modo, referir-se à ambivalência como categoria forte/central em Bauman é vê-lo, enquanto filósofo social e sociólogo da educação, operando numa relação dialética e também hermenêutica; essa possibilidade, segundo Ernildo Stein (2018), opera no horizonte da ciência/do conhecimento. Pensar no horizonte ambivalente é reconhecer a impossibilidade de conclusão definitiva e a não definitividade de encaminhamentos de sínteses, mas sempre de instituição de novas teses, de novas questões, de diálogos. A ambivalência e a ambiguidade passam a ter uma relação de semelhança ou, pelo menos, de proximidade, que autoriza a dizer que o paradigma da ambivalência expressa, também obscuridade de sentido. De alguma forma, hesitação entre duas ou mais possibilidades e, assim, dúvidas, incertezas, indecisões ante os fatos, acontecimentos, situações, a realidade, a condição humana, o mundo comum, conotando a presença do múltiplo/do plural dos significados conexos, ou seja, como conceitos sócio-filosóficos ou sociológicos polissêmicos.

Embora, por vezes, pareça contemplar o movimento dialético, o paradigma da ambivalência é possibilidade, abertura e, assim como a condição humana, considera o contraditório/o oposto como existência possível sem, necessariamente, exigir um esforço de definição. Esse movimento não significa o abandono da proposição, da necessidade de fala/discurso, de argumentação, mas compreende as plurais viabilidades de suas manifestações e, a partir delas, encaminha o diálogo, a alternativa, a solidariedade e outras formas de aprendizado, de pesquisa, de ciência e pensamento, de protagonismo, que educam pelo modo plural de ser. Superar os obstáculos que um discurso monológico, como o hermético de algumas ciências e uma comunicação sistematicamente distorcida na patologia individual e social produzem e apresentam, segue a filosofia habermasiana da necessidade de "entrar num diálogo intelectual com o outro, com aquele que ele $[\mathrm{o} / \mathrm{a}$ outro/a] caracteriza como alguém que "lança pontes e vence distâncias" (HABERMAS, 1987, p. 7).

Para sustentar a afirmação, é possível ver que Zygmunt Bauman pensa a realidade a partir dos paradoxos, das metáforas, e não elege como absoluta nenhuma das condições, pois, em nenhum "porto seguro" se encontra uma verdade teleológica. Permite, com isso, pensar a ambivalência no seu constituinte paradoxal, pois parece estar ciente, na compreensão de Pithan da 
Silva (2015) que "as metáforas permitem luz distinta sobre o real" e "o que são as coisas em si e as formas simbólicas empregadas para compreendê-las". O complexo como busca permanente e ininterrupta da humanidade, pelo conhecimento mais profundo, pleno, amplo e ciente da natural inter-relação entre tudo o que existe - em ato e potência, para usar conceito aristotélico -, porém, sem um "terceiro excluído", mas implicado direta e indiretamente, uma sabedoria para a vida, para garantias pessoais e coletivas.

\section{EM SÍNTESE}

A ambivalência tem sem mostrado, no mundo que compartilhamos e no modo com Bauman organiza suas reflexões, um espaço de contestação, da resistência e do contraditório. A questão, no olhar de Fredric Jameson (2007), é sempre recolocar essas contradições nas pautas alternativas, uma vez que essas agendas podem reacender questões, conceitos e sentidos a cada vez; ressignificar sempre/atualizar/contextualizar e não de uma vez ou definitivamente. Por isso a ambivalência sugere ser um mal-estar da pós-modernidade no oscilar entre liberdade e não segurança, segurança e não liberdade, uma condição do humano, da vida/da existência. Ela, a ambivalência, carrega o movimento dialético e o sentido hermenêutico e com ela é possível pensar e transitar em compreensões do/com o contraditório, porque a dialética envolve categorias de totalidade, contradição e ação recíprocas. Simultaneamente, é possível apreender sentidos e estabelecê-los nessa dinâmica do movimento, da mudança, da transformação. O diálogo com o diferente, entre as distintas tradições de pensamento, se põe não só válida, mas necessária ante a fluidez das relações e a fugacidade do conhecimento, sua transitoriedade, seu valor relativo, lugar de onde é possível situar a "hermenêutica pluralizadora" (BAUMAN, 1998).

A operação paradigmática da ambivalência/plurivalência que se encontra no percurso teórico de Bauman e no modo como desenvolve o seu pensamento analítico, crítico-reflexivo e sócio-filosófico, se institui como mais "una herramienta indispensable" para decodificar e ler os sintomas do mundo contemporâneo (BAUMAN; DESSAL, 2014, p. 149). Por isso, ambivalência contém polissemia em sua essência/natureza. Não no sentido de significar qualquer coisa, mas de assumir vários sentidos possíveis, a partir das várias apreensões e compreensões humanas, portanto, dos diálogos possíveis, dos conhecimentos, das compreensões. Simultaneamente, na liquidez da modernidade, que é também liquidez, fluidez, de sentidos, apropriações e significações particulares, a realidade, as ações, os acontecimentos, os conceitos, podem assumir multiplicidades de significados e de expressões. Bauman vê essa realidade como componente da condição humana, algo intrínseco ao humano e justifica essa posição, por meio de sua "hermenêutica pluralizadora".

É nessa seara que a educação pode ser compreendida, assumida e trabalhada como "pluralidade", não singularização (BAUMAN, 2001, p. 123), e também como multiplicidade, complexidade, movimento, rapidez; paradoxo, volatilidade e ambiguidade. De onde, então, brotam as possibilidades de engajamento, de comunidade, a solidariedade? É desse residual de solidez que decorre a abertura humana para a solidariedade, para a necessidade do aprendizado, da educação, que validam as condições, juntamente com o diálogo, da manutenção, da alternativa e das viabilidades da existência comum, da vida, do instituir (BAUMAN, 2016; 2017; FREIRE, 2014). O mundo é ambivalente embora não concordem seus/suas governantes e colonizadores/as: "As certezas não passam de hipóteses, as histórias não passam de construções, as verdades são apenas estações temporárias numa estrada que sempre leva adiante mas nunca acaba" (BAUMAN, 1999, p. 190). Remete-se, desse modo, à possibilidade educadora da ambivalência, pois, como ensina Bauman, "A ambivalência não é para ser lamentada. Deve ser celebrada. A ambivalência é o limite 
de poder dos poderosos. Pela mesma razão, é a liberdade daqueles que não têm o poder. (BAUMAN, 1999, p. 190).

A ambivalência, na sua aplicação ou ação pedagógica, na educação, indica a possibilidade do contraditório e exige, por vezes, o dissonante, pois, não se assume consenso, tampouco, solidez/absoluto/dogma. Distancia-se do pensamento único, da hegemonia. A ambivalência/plurivalência é abertura à voz do outro/da outra que reivindica o espaço e manifestase como diferente possível e necessário. Ambivalência é abertura para a diferença no sentido de que o humano assim se constitui e pode se reconhecer no outro como outro eu. Desponta nesse cenário, para Pithan da Silva (2015), a ambivalência como "o inacabado do mundo, o que não se deixa dizer do mundo. Está tanto do lado do intérprete quanto do lado do objeto interpretado". Ao ampliar o horizonte da ambivalência, é possível alcançar Marilena Chaú (2014, p. 140), que opera um belo sentido para a ambivalência presente nas relações educacionais, ao escrever que é "na relação com a cultura dominante como cultura instruída, isto é, como "ter estudo" e "ter instrução", que melhor se capta a ambiguidade e a perplexidade dos dominados". Ambivalência à medida que a "cultura instruída é, ao mesmo tempo e na mesma relação, percebida como valor positivo, desejável, um direito, e como negativa porque, impossível de ser conseguida, opera como fonte de discriminação, exclusão e dominação" (CHAUÍ, 2014, p. 140).

Sem um modo único, absoluto, mas com um direcionamento democrático, dialógico, percebe-se a gestação de um paradigma que surge desde a liquidez da modernidade (CASSOL; PITHAN DA SILVA, 2019), e se apresenta como uma possibilidade de resistência às violências das mais variadas formas, às simplificações e homogeneizações sócio-culturais, tradições teóricas e anulações dos indivíduos e suas demandas. Um paradigma que, consciente da sua contingência, da sua incompletude, abre-se ao diálogo com o diferente, com a alteridade e torna-se convite ao novo, ao aprendizado, ao conhecimento, à ciência e a dinamização da racionalidade que pode pensar-se e refazer-se para contribuir com seu feixe de luz nos passos da educação e da solidariedade no mundo que, atualmente, se compartilha.

\section{REFERÊNCIAS}

BAUMAN, Zygmunt. Bauman sobre Bauman: diálogos com Keith Tester. Rio de Janeiro: Zahar, 2011.

BAUMAN, Zygmunt; DESSAL, Gustavo. El retorno del péndulo: sobre psicoanálisis y el futuro del mundo líquido. Buenos Aires: Fondo de Cultura Económica, 2014.

BAUMAN, Zygmunt; BORDONI, Carlo. Estado de crise. Rio de Janeiro : Zahar, 2016.

BAUMAN, Zygmunt. Estranhos à nossa porta. Rio de Janeiro : Zahar, 2017.

BAUMAN, Zygmunt. Modernidade e Ambivalência. Rio de Janeiro: Jorge Zahar, 1999.

BAUMAN, Zygmunt. Modernidade Liquida. Rio de Janeiro: Zahar, 2001.

BAUMAN, Zygmunt. O mal-estar da pós-modernidade. Rio de Janeiro: Zahar, 1998.

BERGUA, José Ange. La verdad es de todos - El testamento cultural de Andrés Ortiz-Osés [entrevista com Andrés Ortiz-Osés]. Disponível no endereço: https://www.religiondigital.org/fratria/VERDAD-testamento-cultural-Andres-OrtizOses_7_2203049686.html. Acesso em 09/02/2020.

CASSOL, Claudionei Vicente. Ambivalência, solidariedade e educação: entre o indivíduo e o social. In.: Revista Brasileira de Educação, vol.25, Rio de Janeiro, 2020, Mar-2020. Disponível no endereço: 
DOI: $10.12957 /$ teias.2022.60595

https://www.scielo.br/scielo.php?script=sci_arttext\&pid=S1413-24782020000100201\&tlng=pt. Acesso em março de 2020.

CASSOL, Claudionei Vicente; PTIHAN DA SILVA, Sidinei. Ambivalência em perspectiva: a questão de um paradigma em gestação no mundo líquido. In.: FÁVERO, Altair; TONIETO, Carina; CONSALTÉR, Evandro. Leituras sobre Zygmunt Bauman e a educação. Curitiba: CRV, 2019. P. 37-54.

CASSOL, Claudionei Vicente Cassol. A missão da filosofia na escola básica. In.: KUIAVA, Evaldo Antônio; SANGALLI, Idalgo José; CARBONARA, Vanderlei (orgs). Filosofia, formaşão docente e cidadania. Ijuí: Ed. Unijuí, 2008. P. 143-163.

CASTORIADIS, Cornelius. Figuras do pensável: as encruzilhadas do labirinto, Vol. VI. Rio de Janeiro : Civilização Brasileira, 2004.

CHAUÍ, Marilena. Conformismo e resistência. Belo Horizonte: Autêntica; São Paulo: Fundação Perseu Abramo, 2014.

DEMO, Pedro. Certeza da Incerteza: ambivalência do conhecimento e da vida. Brasília: Plano, 2000. FREIRE, Paulo. Pedagogia da solidariedade. 2.ed. São Paulo : Paz e Terra, 2014.

GRAMSCI, Antonio. Escritos Políticos, (vol. 1. 1910-1920). Rio de Janeiro: Civilização Brasileira, 2004.

HABERMAS, Jürgen. Dialética e hermenêutica - para a crítica da hermenêutica de Gadamer. Porto Alegre: L\&PM, 1987.

JAMESON, Fredric. Pós-Modernismo: a lógica cultural do capitalismo tardio. 2.ed. São Paulo: Ática, 2007.

PITHAN DA SILVA, Sidinei. Educação, Diferença e Emancipação. Cadeira desenvolvida no PPGEC/Doutorado, 2015-II. Unijuí, 2015.

SINGLY, François de. Uns com os outros: quando o individualismo cria laços. Lisboa: Instituto Piaget, 2006.

STEIN, Ernildo. Dialética e Hermenêutica: uma controvérsia sobre o método em Filosofia. In: Sintese Revista de Filosofia, v. 10, n. 29, p. 21-48, 1983, disponível no endereço: http://periodicos.faje.edu.br/index.php/Sintese/issue/view/184, acesso em 18/04/2018.

VANI, Juliana. Educaşão no horiz̧onte da solidariedade: a doação de órgãos e compromisso com o outro. 131 páginas. Dissertação. Mestrado em Educação nas Ciências, Universidade Regional do Noroeste do Estado do Rio Grande do Sul - UNIJUÍ, Ijuí-RS, 2019. Disponível no endereço: https://virtual.unijui.edu.br/Portal/Modulos/modeloInformacoes/?RH5sv44knZhFMK3qARF 6zZdE0eF6wpdiPnmCIBzvbmQcLoFPazpNDqYD1TJtbRGOP8_SLA_hubQjaWCcShPZaF Rsyw_IGL__=\#. Acesso em julho de 2020.Seção secundária 


\section{Informações do(a)(s) autor(a)(es)}

Claudionei Vicente Cassol

Professor na Universidade Regional Integrada do Alto Uruguai e das Missões - URI, campus de Frederico Westphalen-RS, Brasil e no CEEDO - Cerro Grande-RS. Integrante do Grupo Biosofia (Pesquisas e Estudos em Filosofia), URI-FW.

E-mail:cassol@uri.edu.br

ORCID: https://orcid.org/0000-0001-7837-887X

Link Lattes: http://lattes.cnpq.br/6978565796991115 